\title{
Towers Handbook
}

D R Cook

January 2016 


\section{DISCLAIMER}

This report was prepared as an account of work sponsored by the U.S. Government. Neither the United States nor any agency thereof, nor any of their employees, makes any warranty, express or implied, or assumes any legal liability or responsibility for the accuracy, completeness, or usefulness of any information, apparatus, product, or process disclosed, or represents that its use would not infringe privately owned rights. Reference herein to any specific commercial product, process, or service by trade name, trademark, manufacturer, or otherwise, does not necessarily constitute or imply its endorsement, recommendation, or favoring by the U.S. Government or any agency thereof. The views and opinions of authors expressed herein do not necessarily state or reflect those of the U.S. Government or any agency thereof. 


\section{Towers Handbook}

D R Cook

January 2016

Work supported by the U.S. Department of Energy, Office of Science, Office of Biological and Environmental Research 


\section{Contents}

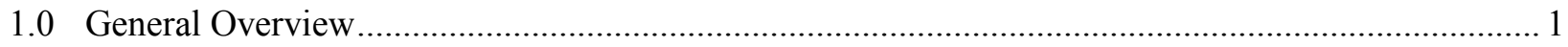

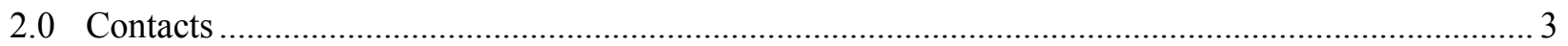

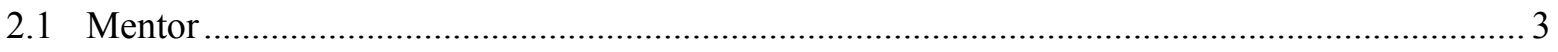

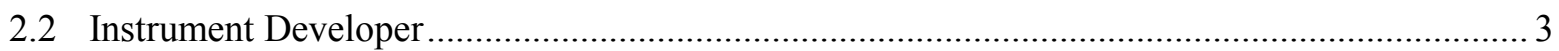

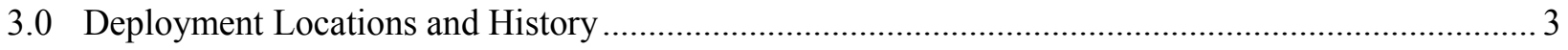

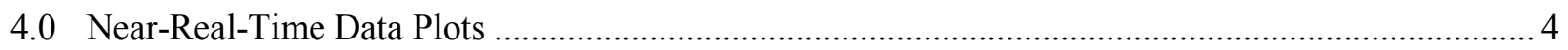

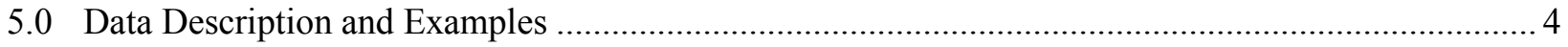

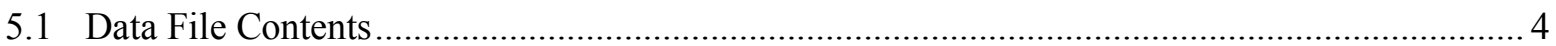

5.1.1 Primary Variables and Expected Uncertainty ............................................................ 4

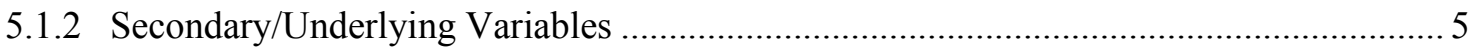

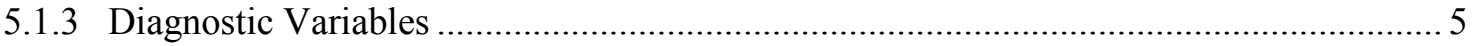

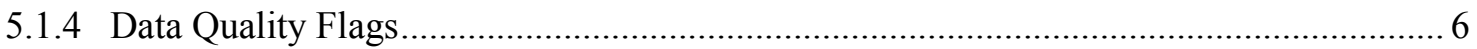

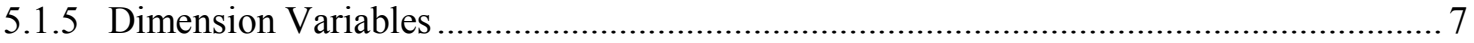

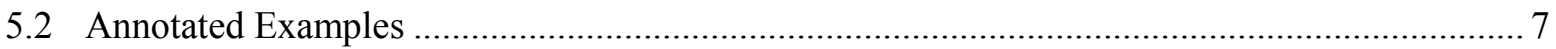



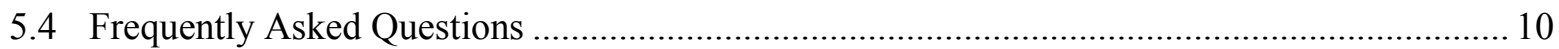

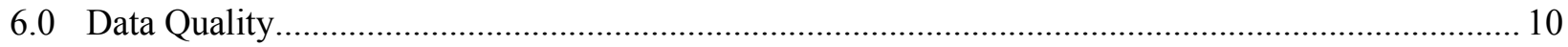

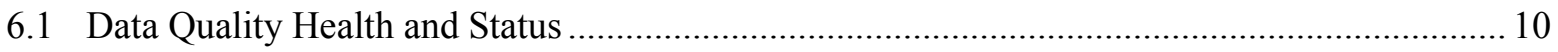

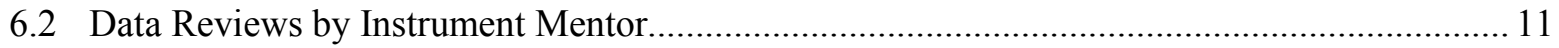

6.3 Data Assessments by Site Scientist/Data Quality Office ..................................................... 11

6.4 Value-added Procedures and Quality Measurement Experiments ......................................... 13

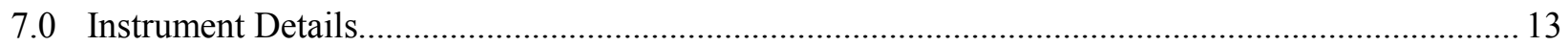

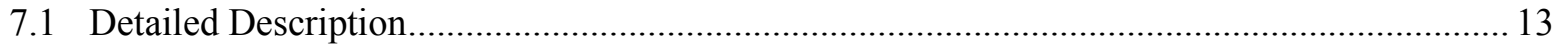



7.1.2 System Configuration and Measurement Methods ................................................... 15

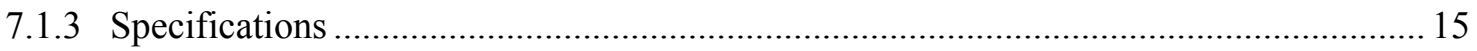

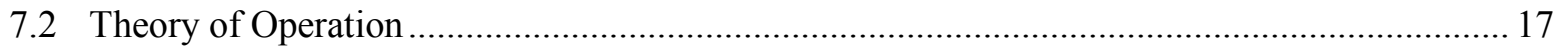

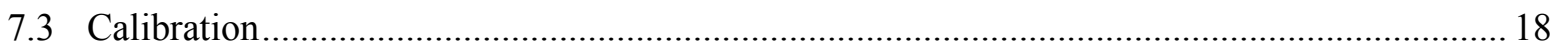

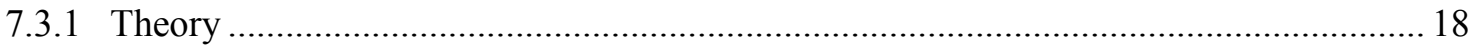

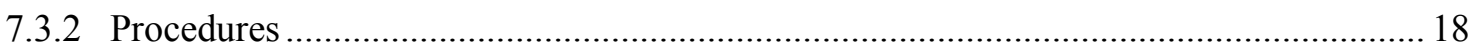

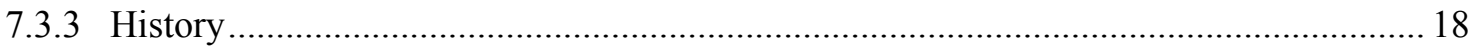

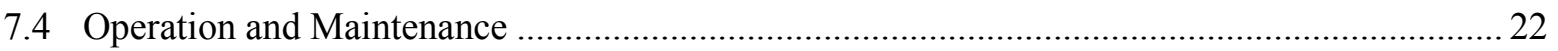

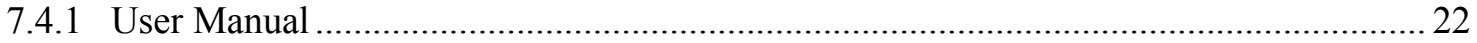

7.4.2 Routine and Corrective Maintenance Documentation ................................................. 23

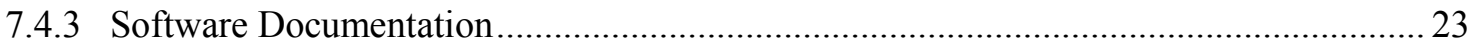

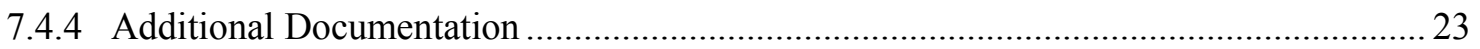

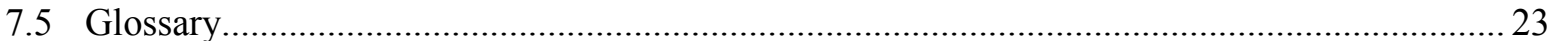

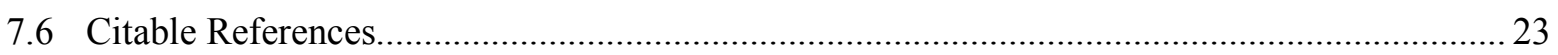




\section{Figures}



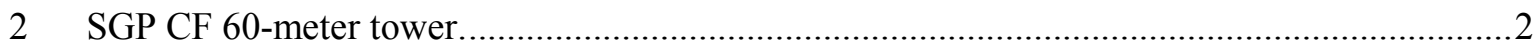

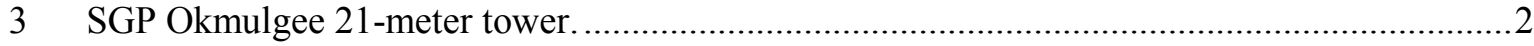

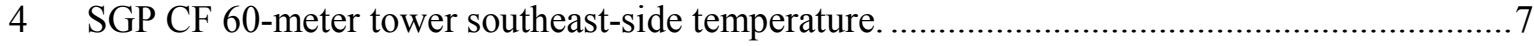



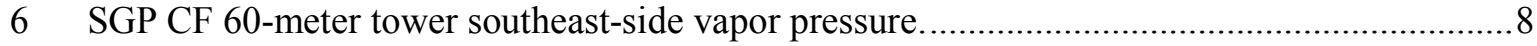

\section{Tables}

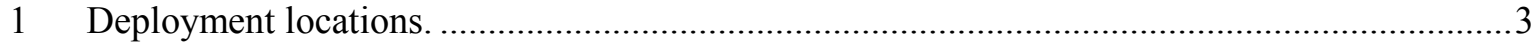




\subsection{General Overview}

Three tall towers are installed at the Atmospheric Radiation Measurement (ARM) Climate Research Facility: a 60-meter triangular tower at the Southern Great Plains (SGP) Central Facility (CF), a 21-meter walk-up scaffolding tower at the SGP Okmulgee forest site (E21), and a 40-meter triangular tower at the North Slope of Alaska (NSA) Barrow site. The towers are used for meteorological, radiological, and other measurements. Instrument systems installed on the towers are listed in Section 7, and instrument details are listed below, although only the Temperature/Relative Humidity/Vapor Pressure (T/RH/VP) measurements made on the SGP CF tower are described in detail. Meteorological measurements made on the NSA 40-meter tower can be found at http://www.arm.gov/instruments/met. Photographs of each tower are provided below.

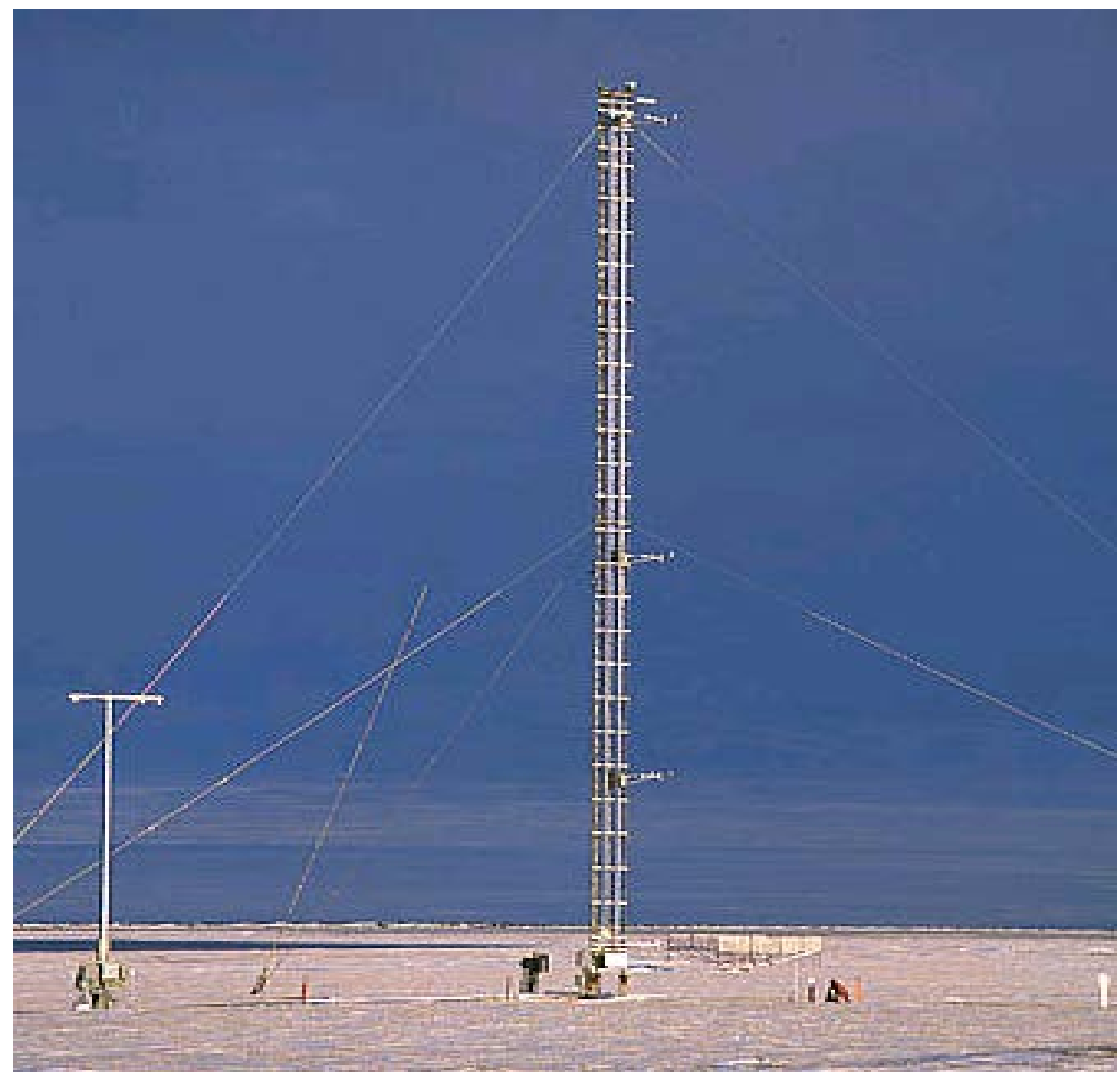

Figure 1. NSA Barrow 40-meter tower. 


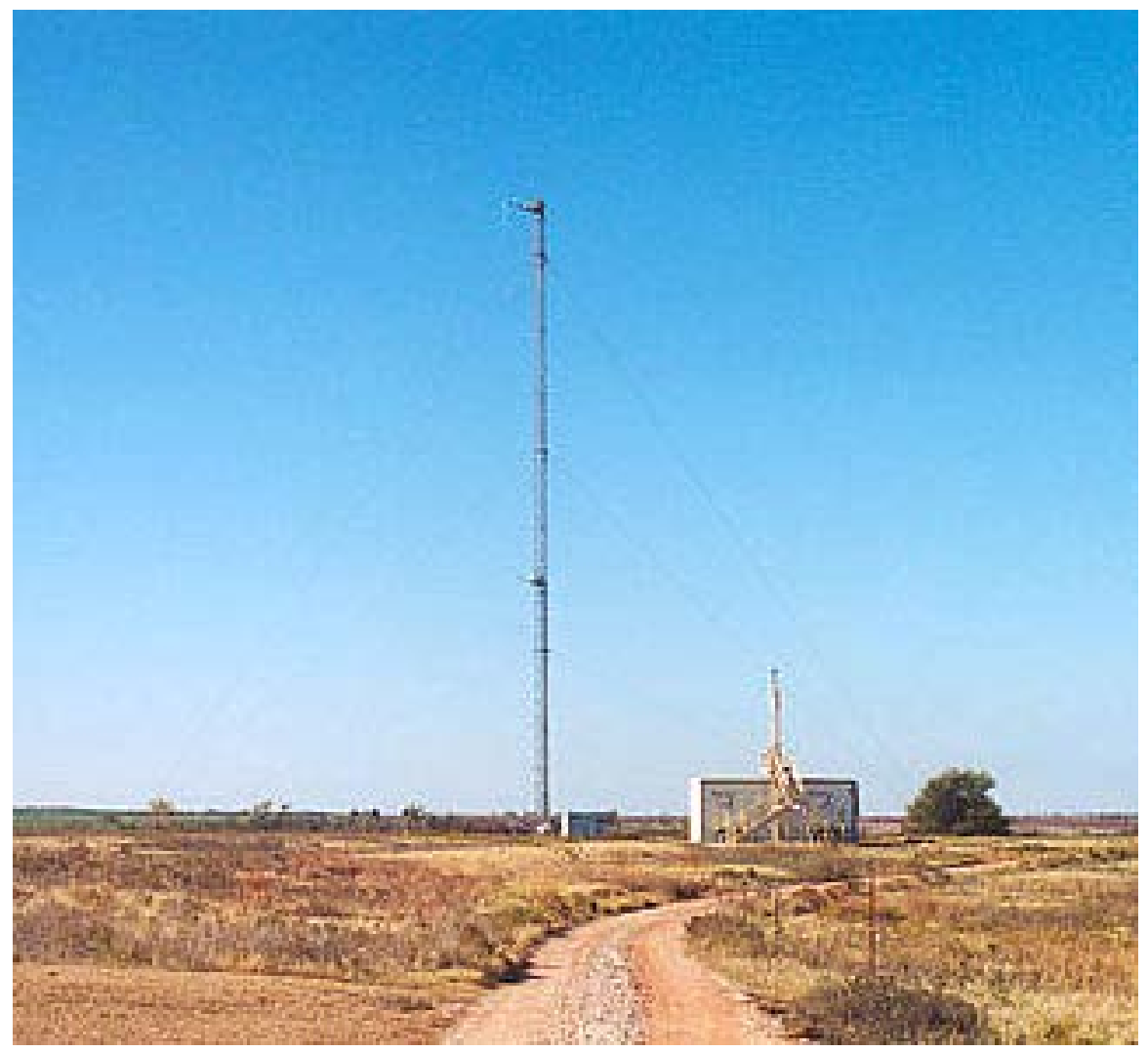

Figure 2. SGP CF 60-meter tower.

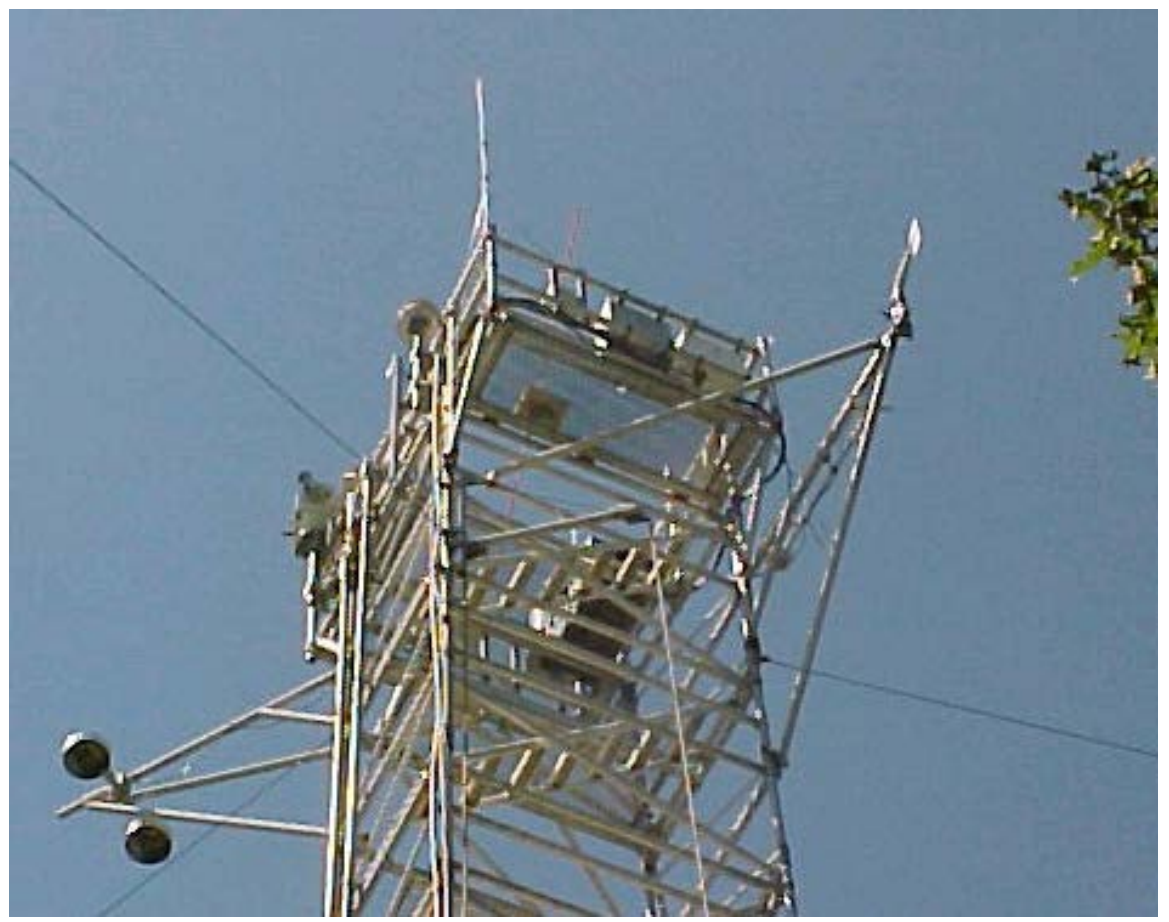

Figure 3. SGP Okmulgee 21-meter tower. 


\subsection{Contacts}

\subsection{Mentors}

David R. Cook

Environmental Science Division

Argonne National Laboratory, Bldg. 240

Argonne, Illinois 60439

Phone: (630) 252-5840

Fax: (630) 252-2959

drcook@anl.gov

Jenni Kyourac

Environmental Science Division

Argonne National Laboratory

Argonne, Illinois 60439

Phone: (815) 347-6969

jprell@anl.gov

\subsection{Instrument Developer}

Different tower manufacturers and installers provided the three towers. For more information on the tower manufacturers and installers, please contact the tower mentor. For information on the vendors of the individual instrument systems mounted on the NSA and SGP Okmulgee towers, please contact the mentors for those instrument systems. Each tower receives a thorough inspection every two years; this inspection is conducted by Tower Systems, Inc. for the SGP CF and NSA Barrow towers, and by the mentor for the SGP Okmulgee tower.

A list of the instruments and instrument vendors for the SGP CF 60-meter and NSA Barrow 40-meter towers measurement systems is found in Section 7.1.1 List of Components.

\subsection{Deployment Locations and History}

Table 1. Deployment locations.

\begin{tabular}{|c|c|c|c|c|c|}
\hline $\begin{array}{c}\text { ARM Facility } \\
\text { Site }\end{array}$ & Location & $\begin{array}{c}\text { Tower } \\
\text { Structure }\end{array}$ & Manufacturer & Installer & $\begin{array}{c}\text { Date } \\
\text { Installed }\end{array}$ \\
\hline NSA & Barrow, AK & $\begin{array}{c}44 \text {-inch } \\
\text { triangular }\end{array}$ & $\begin{array}{c}\text { Sabre } \\
\text { Communications, Inc. }\end{array}$ & $\begin{array}{c}\text { Tower } \\
\text { Systems, Inc. }\end{array}$ & $\begin{array}{c}\text { May } \\
1997\end{array}$ \\
\hline SGP & $\begin{array}{c}\text { Central } \\
\text { Facility, } \\
\text { (Lamont, OK) }\end{array}$ & $\begin{array}{c}42 \text {-inch } \\
\text { triangular }\end{array}$ & Rohn, Inc. & $\begin{array}{c}\text { Tower } \\
\text { Systems, Inc. }\end{array}$ & $\begin{array}{c}\text { December } \\
1992\end{array}$ \\
\hline SGP & Okmulgee, & aluminum & UpRight, Inc. & East Coast & July \\
\hline
\end{tabular}




\begin{tabular}{|c|c|c|c|c|c|}
\hline & OK & scaffolding & $\begin{array}{c}\text { (provided by Horizon } \\
\text { High Reach, Inc.) }\end{array}$ & $\begin{array}{c}\text { Rigging and } \\
\text { Contracting } \\
\text { Company, Inc. }\end{array}$ & 1997 \\
\hline
\end{tabular}

\subsection{Near-Real-Time Data Plots}

To view near-real-time plots of data from instrument systems on the towers, visit the NCV website at http://dq.arm.gov/ncvweb/ncvweb.cgi.

\subsection{Data Description and Examples}

\subsection{Data File Contents (SGP CF 60-meter tower only)}

Only data from the T/RH/VP measurements made on the SGP CF 60-meter tower are described below. Although the tower was erected in December 1992, T/RH instruments were not installed until March 1993. For other measurements made on this tower or on the SGP Okmulgee and NSA 40-meter towers, see the websites of the individual instrument systems.

\subsubsection{Primary Variables and Expected Uncertainty}

West elevator, 25-meter level (sgp1twr25m, sgp30twr25m datastreams):

1 and 30 minute:

Temperature (temp): $+/-0.2^{\circ} \mathrm{C}$

Relative humidity (rh) +/- 2\% (0-90\% RH), +/- 3\% (90-100\% RH)

Vapor Pressure (vap_pres)

West elevator, 60-meter level (sgp1twr60m, sgp30twr60m datastreams):

1 and 30 minute:

Temperature (temp): $+/-0.2^{\circ} \mathrm{C}$

Relative humidity (rh): $+/-2 \%(0-90 \% \mathrm{RH}),+/-3 \%(90-100 \% \mathrm{RH})$

Vapor Pressure (vap_pres)

Southeast elevator, 25-meter and 60-meter levels (sgp1twr10x, sgp30twr10x datastreams):

1 and 30 minute:

Temperature (temp_25m, temp_60m): $+/-0.2^{\circ} \mathrm{C}$

Relative humidity (rh_25m, rh_60m): $+/-2 \%(0-90 \% \mathrm{RH}),+/-3 \%(90-100 \% \mathrm{RH})$

Vapor Pressure (vap_pres_25m, vap_pres_60m)

Note: Vapor pressure is calculated from the temperature and relative humidity measurements. Uncertainties have not been provided by the sensor manufacturers; therefore, $\mathrm{T}$ and $\mathrm{RH}$ accuracies provided by the manufacturer have been quoted instead. 


\subsubsection{Definition of Uncertainty}

We define uncertainty as the range of probable maximum deviation of a measured value from the true value within a $95 \%$ confidence interval. Given a bias (mean) error $B$ and uncorrelated random errors characterized by a variance $\sigma^{2}$, the root-mean-square error (RMSE) is defined as the vector sum of these:

$$
R M S E=\left(B^{2}+\sigma^{2}\right)^{1 / 2}
$$

( $B$ may be generalized to be the sum of the various contributors to the bias and $\sigma^{2}$ the sum of the variances of the contributors to the random errors).

To determine the $95 \%$ confidence interval we use the Student's $t$ distribution: $t_{\mathrm{n} ; 0.025} \approx 2$, assuming the RMSE was computed for a reasonably large ensemble. Then the uncertainty is calculated as twice the RMSE.

\subsubsection{Secondary/Underlying Variables}

This section is not applicable to this instrument.

\subsubsection{Diagnostic Variables}

West elevator, 25-meter level (sgp1twr25m, sgp30twr25m datastreams):

\section{1 minute:}

Aspirator status (aspirator)

Battery voltage (vbat)

\section{0 minute:}

Standard deviation of temperature (sd_temp)

Standard deviation of relative humidity (sd_rh)

Standard deviation of vapor pressure (sd_vap_pres)

Aspirator status (aspirator)

\section{West elevator, 60-meter level (sgp1twr60m, sgp30twr60m datastreams):}

\section{1 minute:}

Aspirator status (aspirator)

Battery voltage (vbat)

\section{0 minute:}

Standard deviation of temperature (sd_temp)

Standard deviation of relative humidity (sd_rh)

Standard deviation of vapor pressure (sd_vap_pres)

Aspirator status (aspirator)

Southeast elevator, 25-meter and 60-meter levels (sgp1twr10x, sgp30twr10x datastreams): 


\section{1 minute:}

Battery voltage (vbat)

\section{0 minute:}

Standard deviation of 25-meter temperature (sd_temp_25m)

Standard deviation of 25-meter relative humidity (sd_rh_25m)

Standard deviation of 25-meter vapor pressure (sd_vap_pres_25m)

Standard deviation of 60-meter temperature (sd temp_60m)

Standard deviation of 60-meter relative humidity (sd_rh_60m)

Standard deviation of 60 -meter vapor pressure (sd_vap_pres_60m)

Note: The aspirator status levels for the west elevator are set in the CR10X datalogger programming to a level that will always indicate that the aspirators are working. It was found that a reliable indication of aspirator status was not possible with the long cable lengths on the tower. Therefore, the aspirator status diagnostic variable is of no practical use; it is maintained only to preserve the datastream form used since the T/RH system was installed in 1993.

\subsubsection{Data Quality Flags}

West elevator, 25-meter level (sgp30twr25m datastream):

30 minute:

qc_temp

qc_rh

qc_vap_pres

qc_aspirator

West elevator, 60-meter level (sgp30twr60m datastream):

\section{0 minute:}

qc_temp

qc_rh

qc_vap_pres

qc_aspirator

Southeast elevator, 25-meter and 60-meter levels (sgp30twr10x datastream):

30 minute:

qc_temp_25 m

qc_rh_25 m

qc_vap_pres_25 m

qc_temp_60 m

qc_rh_60 m

qc_vap_pres_60 m 


\subsubsection{Dimension Variables}

Note: lat, lon, and alt refer to the ground surface, not to the instrument system height.

1 and 30 minute:

lat

lon

alt

base_time

time_offset

\subsection{Annotated Examples}

The following plots of 25-meter and 60-meter temperature, relative humidity, and vapor pressure on August 1 and 2, 2004, show normal diurnal variations for summertime. During nighttime hours, a temperature inversion sets up, resulting in a reversal in sign of the daytime relative humidity profile. Note the lack of dependence of vapor pressure on temperature and relative humidity.

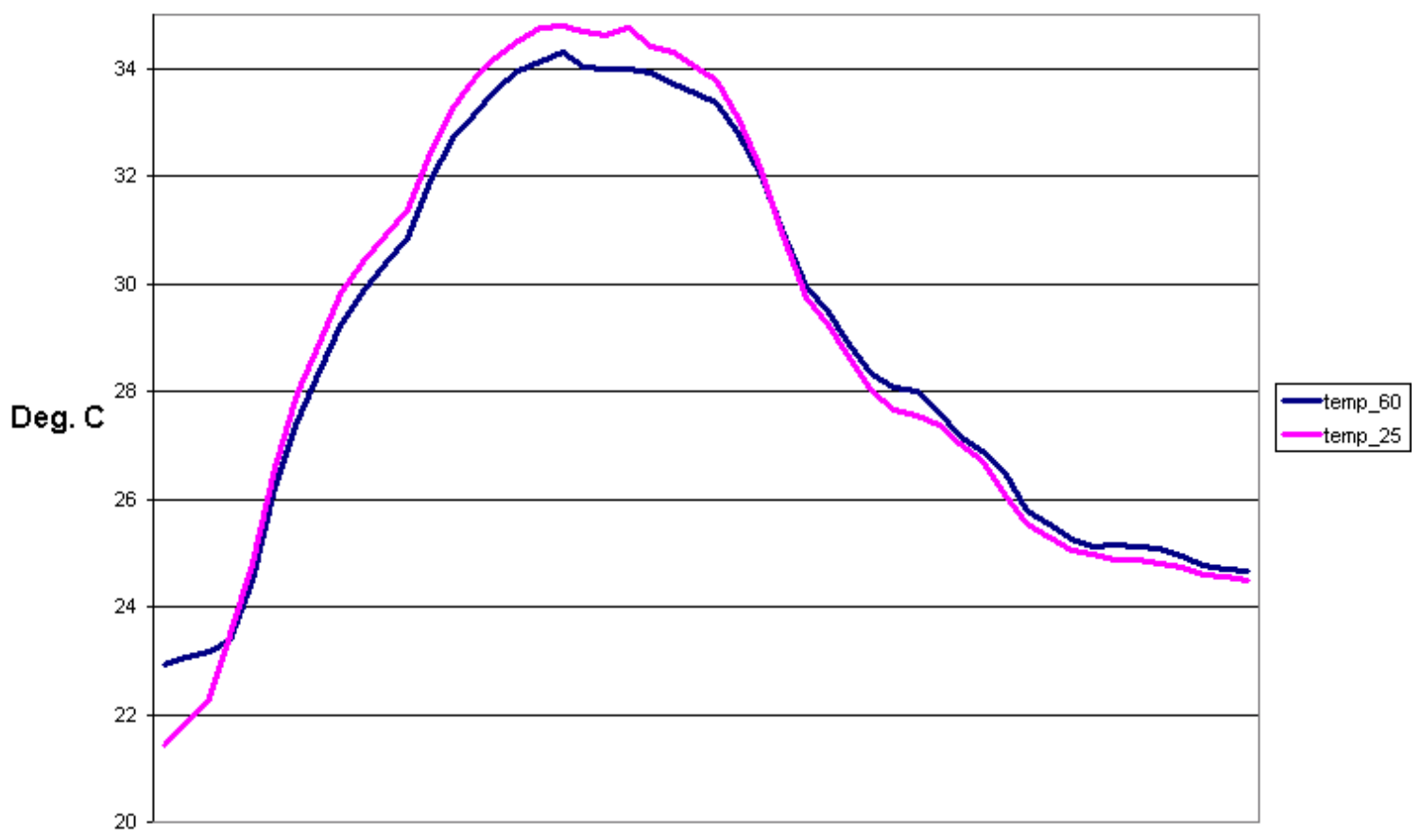

Figure 4. SGP CF 60-meter tower southeast-side temperature. 


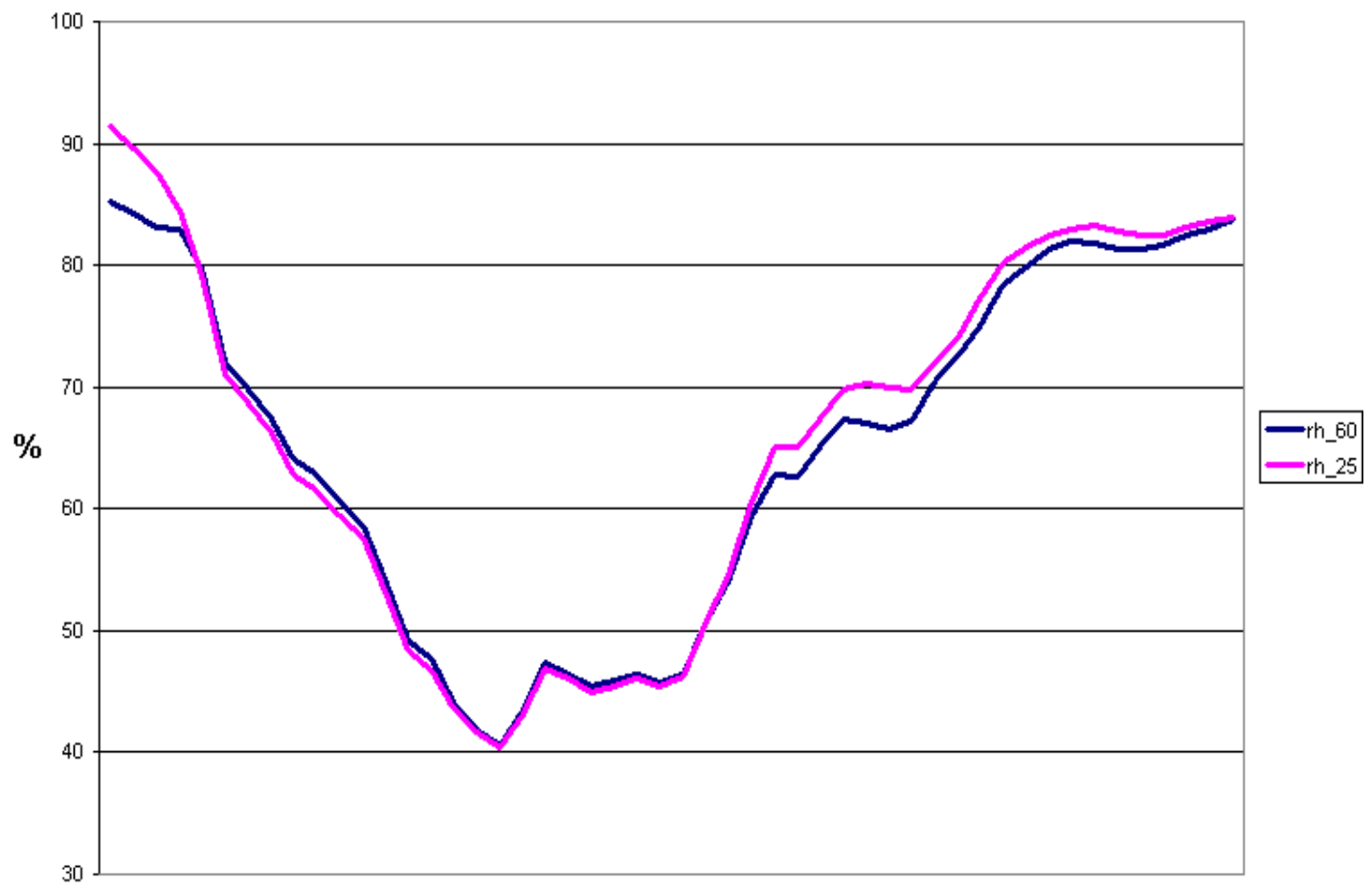

Figure 5. SGP CF 60-meter tower southeast-side relative humidity.

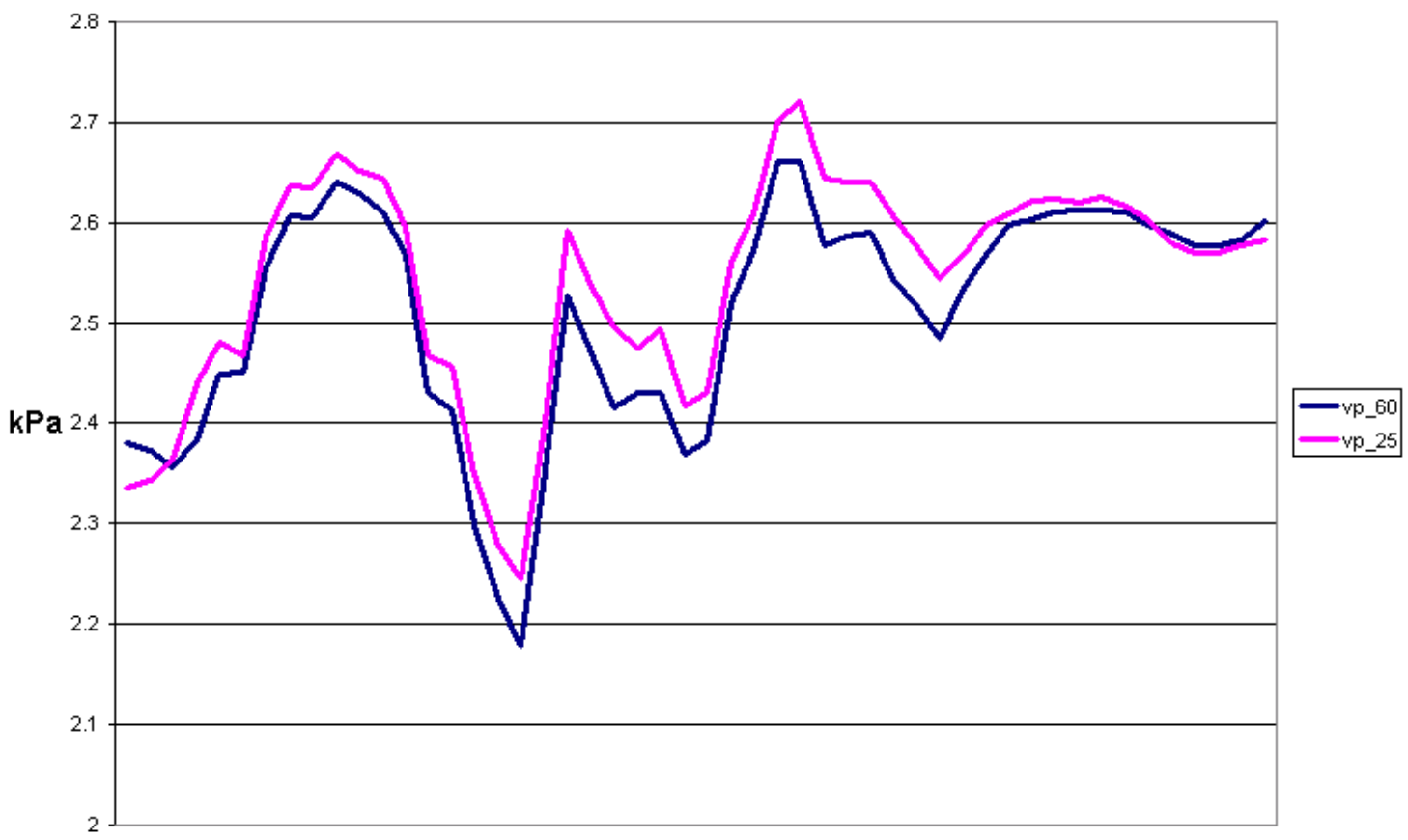

Figure 6. SGP CF 60-meter tower southeast-side vapor pressure. 


\subsection{User Notes and Known Problems}

The elevator systems used on the SGP CF 60-meter tower and the NSA Barrow 40-meter tower are robust. However, the receiver brackets on the SGP CF tower have at times bent under frequent use, which causes a loss of ability to make an electronic connection between an elevator carriage connector and the tower receiver, resulting in some data loss. Maintenance by the installer has been required to fix this problem on several occasions.

Fortunately, this situation has not yet happened at the NSA Barrow tower.

There were significant periods of poor relative humidity measurements on the SGP CF tower before September 1996, when the Qualimetrics probes were in use on the west elevator system and did not have the correct conversion to engineering units in the datalogger programming. Much of this stemmed from incorrect calibrations performed by the manufacturer. These inconsistencies were discovered normally in the data after installation of the relative humidity probe. Sometimes this was recognized during the sixmonth calibration, and the calibration was adjusted in the datalogger programming. However, at times, these adjustments have only corrected the data below about $90 \%$ relative humidity, with no sensitivity resulting for relative humidity above $90 \%$. One reason for this has been determined to be the calibration procedure used by the manufacturer, who calibrated the sensors at three relative humidities, but did not check the performance at $0 \%$ or $97 \%$. Since the sensor is less than linear above $90 \%$, a check above $90 \%$ must be used to ensure that the slope has been properly set for the entire operating range of the sensor.

Since September 1996, Vaisala, Inc. HMP35D or HMP45D T/RH probes have been used on the tower; these sensors are sent to Vaisala, Inc. for calibration annually. Each relative humidity probe is now replaced and recalibrated annually. The Vaisala probes do not usually exhibit any abnormal characteristics. However, the Vaisala probes installed on the west side of the tower in August 2003 had an abnormally high relative humidity bias, which ramped up to as much as $13 \%$ excess relative humidity at 60 -meter on the west elevator after a few months. This probe had to be replaced to ensure accurate measurements.

Temperature comparisons between the southeast and west sensors on the SGP CF tower can show some differences. Strong solar heating can cause the west-side temperatures to be slightly higher than the southeast-side temperatures and the west-side relative humidities to be lower than the southeast-side humidities. This is seen most frequently during the summer.

The connections between the SGP CF tower west-side tower instruments at 25 meters and 60 meters and the dataloggers were accidentally reversed from May 19, 1999, until September 20, 2000 (see discussion in DQR D001011.1). This caused measurements from 25 meters to be recorded in datastreams, files, and data fields labeled as 60 meters, and vice versa. Because the data values were valid measurements, but were labeled incorrectly, it was difficult to identify this error during data analysis. These data have been reprocessed to place them at the correct levels; the corrected data are what is found in the ARM Archive.

The sensors on the NSA Barrow tower are subject to freeze-up at times during the winter. Rime ice easily builds up on the instrumentation, causing blocking of the inlet to the T/RH probes and interference of the measurements of the chilled mirror hygrometer and present weather detector. The sonic anemometers are heated and therefore do not accumulate rime ice. 
The SGP Okmulgee tower is situated in a forest and is therefore subject to vulture roosting. The bird droppings caused a deterioration of a number of measurements, including radiometry, precipitation, sonic anemometry, etc. Numerous deterrents were tried without much success until bird spikes and rotating shafts were installed; these have worked well since early 2004.

The original booms on the SGP Okmulgee tower were difficult to operate. Therefore, new booms manufactured by Tower Systems, Inc. were installed in 2003 and have proved to work much better.

\subsection{Frequently Asked Questions}

\section{What does the aspirator value represent?}

The aspirator status value on the west side of the SGP CF tower indicates whether aspiration of the T/RH and PRTD probes is sufficient to produce good-quality measurements of temperature and relative humidity. The aspiration rate must exceed a certain value to prevent errors from heating of the sensors by solar radiation impinging on the aspirator radiation shield. A complication prevents the aspirator value from accurately indicating aspiration status; long cable lines on the tower require use of a marginal limit value for aspiration status in the datalogger program that serves the tower temperature and relative humidity system. Therefore, wind speeds in excess of about 10 meters per second used to produce (before May 24, 1996) a false aspirator status indication. A change in the aspiration limit value in the CR10X programs has effectively resulted in aspiration status being continuously good. See the discussion of this issue in the note at the end of Section 5.1.3.

2. Which measurements are the most accurate - those from the southeast side or from the west side?

Data users are advised to use the southeast side measurements, unless only the west side measurements are available or correct. This is because the aspiration and radiation shielding of the probes on the southeast side are better than on the west side. The aspiration rate of the aspirators on the west side is barely adequate, resulting in west-side temperatures being up to a degree too high and relative humidities being too low during low wind and high solar radiation conditions, particularly during the summer.

\subsection{Data Quality}

\subsection{Data Quality Health and Status}

The status of the measurements made by the meteorological instruments on the SGP CF 60-meter and NSA Barrow 40-meter towers can be found by going to the ARM Data Quality Explorer website at (http://dq.arm.gov/dq-explorer/cgi-bin/main) or NCVweb for interactive data plotting (https://plot.dmf.arm.gov/ncvweb/ncvweb.cgi). 


\subsection{Data Reviews by Instrument Mentor}

Monthly reviews of the SGP CF 60-meter and NSA Barrow 40-meter tower data were prepared by the mentor and submitted to the Instrument Mentor Monthly Summary (IMMS) database (http://www.db.arm.gov/IMMS/) until late 2014. These reports are also accessible from the Documentation section on the Towers and MET web sites (www.arm.gov/instruments/twr, www.arm.gov/instruments/met).

Beginning in FY2006, Data Quality Reports (DQRs) are not written for missing data or for situations when QC flags clearly show that the data are incorrect. DQRs are written for periods when the tower carriages are down; in this case, QC flags often do not appear in the data, and it is not obvious that the data should have been flagged as incorrect.

\subsection{Data Assessments by Site Scientist/Data Quality Office}

The following guidance has been provided by the SGP 60-meter tower mentor for use by the DQ Office in preparing their weekly assessment report for the SGP 60-meter tower temperature and humidity systems.

\section{0-meter Tower Data Quality Guidance}

\section{David R. Cook}

2 November 2005

Introduction: The best way to tell someone what to look for in assessing the tower data is to describe conditions that reflect correct and incorrect data. For the most part, the QC checks provide adequate guidance. However, there are conditions for which legitimate values fall outside the QC limits. Therefore, please use the following information as further guidance.

\section{Primary Measurements:}

West elevator, 25-meter level (sgp 1twr25m, sgp30twr25m datastreams):

temp (temperature)

rh (relative humidity)

vap_pres (vapor pressure)

West elevator, 60-meter level (sgp1twr60m, sgp30twr60m datastreams):

temp (temperature)

rh (relative humidity)

vap_pres (vapor pressure)

Southeast elevator, 25-meter and 60-meter levels (sgp1twr10x, sgp30twr10x datastreams):

temp_25m (25-meter temperature)

temp_60m (60-meter temperature)

rh_25m (25-meter relative humidity)

rh_60m (60-meter relative humidity)

vap_pres_25m (25-meter vapor pressure) 
vap_pres_60m (60-meter vapor pressure)

Nuisance QC Flags: The aspirator (aspirator status) QC flag may trip for the west side 25 meters or 60 meters. However, the aspirator status levels are set in the CR10X datalogger programming so that they will always indicate that the aspirators are working. A reliable indication of aspirator status was impossible with the long cable lengths on the tower. Therefore, the aspirator status diagnostic variable is useless; it is maintained only to preserve the datastream form used since the T/RH system was installed in 1993. Therefore, the aspirator QC flag condition should not be reported in the DQO assessment reports.

Comparison of Data between the West and Southeast Sides: The measurements can generally be favorably compared between the two sides of the tower. However, the west-side aspirator shields are made of metal (the southeast-side shields are plastic), absorb more solar radiation than the southeast-side aspirators do, and tend to cause the west-side temperature to be just slightly higher than the southeast side and west-side relative humidity to be slightly lower during high solar and warm weather conditions (primarily summer). When the temperature difference between the two sides and at the same height differs by more than $2^{\circ} \mathrm{C}$, this should be reported in the assessment report. When the relative humidity difference between the two sides and at the same height differs by more than 10 percent, this should be reported in the assessment report.

Comparison of Data with the Surface Meteorological Instrumentation (MET) and Energy Balance Bowen Ratio (EBBR): Caution must be used in comparing the tower temperature and relative humidity measurements with the E13 MET and EBBR (both in the CF central cluster) measurements. First, they usually see different vegetation surfaces; this is true for virtually all wind directions. Second, they are at different heights (MET and EBBR temperature and humidity measurements are at $\sim 2$ meters). At times, the 60-meter level of the tower is de-coupled atmospherically from the surface, resulting in very large differences in measurements between the MET, EBBR, and the two levels of the tower.

Comparison of Data with the SONDE: The SONDE is launched some distance away from the tower and, depending on the wind direction and speed, the sonde could be located very far away from the tower when it reaches the 25-meter and 60-meter heights. Therefore, one cannot expect that the SONDE measurements of temperature and relative humidity will be exceptionally similar to the tower measurements. Furthermore, the SONDE sensors do not respond rapidly to strong gradients in temperature and relative humidity that often occur in the lower 60 meters of the atmosphere; they tend to lag the actual temperature and relative humidity. When the vertical gradients of temperature and relative humidity are strong, large differences will be seen between the SONDE and tower measurements.

\section{Common Conditions Reflecting Correct or Incorrect Data:}

a. Occasionally, the tower elevators experience hardware or electronic problems, such as when an elevator carriage connector does not mate properly with the receiver on the tower. In this case, some or all of the measurements at that level have been incorrect. If this condition seems obvious (especially when comparing data between the two sides of the tower), please report it in the assessment report.

b. If datalogger battery voltage (vbat in the one-minute datastream) is less than 10.5 volts, all measurements are unreliable and can be considered incorrect.

c. Since the aspirator status for the west-side 25 -meter and 60-meter levels is useless, the data should not be considered correct or incorrect based on this value. 
d. Occasionally a relative humidity probe will become saturated with moisture, resulting in a measurement of $98 \%$ or more for many hours. When this condition persists for more than several hours, a hysteresis can occur in the recovery of the sensor from saturated conditions. The relative humidity may read too high for as much as a day afterward. This condition can usually be detected from looking at the other relative humidity measurements on the tower or from comparison with the EBBR and SMOS measurements.

\subsection{Value-added Products and Quality Measurement Experiments}

Tower-related value-added products or VAPs that use SGP CF tower data as input include:

TWRMR (computes water vapor mixing ratio at the surface and at the 25-meter and 60-meter tower levels; needed as input to RL PROF MR, and hence RLPROF BE)

RLPROF suite, specifically RLPROFMR (25-meter- and 60-meter-level tower in situ measurements of moisture are used as input)

Tower-related QMEs or QMEs that use tower data as input include:

QMEAERIPROF (25-meter and 60-meter tower in situ measurements of temperature and vapor pressure are used as inputs)

\subsection{Instrument Details}

\subsection{Detailed Description}

\subsubsection{List of Components}

\section{SGP CF 60-meter tower:}

Vaisala HMP35D or HMP45D T/RH probes (west side at 25 meters and 60 meters, east side at 25 meters and 60 meters), in aspirators. (Qualimetrics, Inc. T/RH probes were used on the west elevator levels until September 1996 - west elevator T/RH/VP measurements from 1993 through most of August 1996 are of questionable quality.)

Minco Products Inc., Model S853PD60X72 $100 \mathrm{ohm}$ PRTD temperature probes at 25 meters and 60 meters on the west side, in aspirators.

Qualimetrics, Inc. Model 8151-B motorized aspirated radiation shield with Qualimetrics, Inc. Model T450009 flow sensor at 25 meters and 60 meters on the west side.

R.M. Young Model 43408/43482 motor-aspirated radiation shield at 25 meters and 60 meters on the southeast side. 
Campbell CR10X dataloggers and communication interface equipment: one each per 25 meters west level, 60 meters west level, southeast side. (CR21X dataloggers were used before August 8, 2001.)

IRT (Infrared Thermometer), upwelling, 25 meters, southeast side.

PSP (Precision Spectral Pyranometer), upwelling, 25 meters, southeast side, logged into the sgpirt25mC1 datastream.

PIR (Precision Infrared Radiometer), upwelling, 25 meters, southeast side, logged into the sgpirt25mC1 datastream.

MFR (Multi-Filter Radiometer), upwelling, 25 meters, southeast side.

GPS (global positioning system) repeater antenna, 60 meters, southeast side.

PGS (Precision Gas System), attached to tower structure at 2, 4, 25 and 60 meters, north side.

$\mathrm{CO}_{2} \mathrm{FLX}$ (Carbon Dioxide Flux Measurement Systems), 25 meters and 60 meters, west side.

SGP Okmulgee 21-meter tower (see individual instrument system sites for details):

MET (Surface Meteorological Instrumentation)

ECOR (Eddy Correlation System)

SIRS (Solar and Infrared Station)

\section{NSA Barrow 40-meter tower:}

Camera that takes photographs of the tundra surface south of the tower, installed at 40 meters, south side.

\section{Original MET instrumentation:}

Technical Services Laboratory, Inc. Model 1088 chilled mirror hygrometer at 3 meters, attached to the north leg of the tower. (Previously Meteolabor AG VTP6 Ventilated Thermohygrometer chilled mirror hygrometer at 3 meters, attached to the north leg of the tower, removed in October 2003.)

PWD12 Present Weather Detector measures visibility, precipitation, and precipitation type at $2 \mathrm{~m}$, located north of the tower. (Vaisala, Inc. FD12P Present Weather Sensor was used prior to Summer 2010.)

Vaisala, Inc. WS425 sonic anemometer measures horizontal wind speed and direction at 2, 10, 20, and 40 meters, northeast side. (Prior to September 2008, wind speed was measured with a Vaisala, Inc. WAA251 cup anemometer, and wind direction was measured with a Vaisala, Inc. WAV251 wind vane.)

Vaisala, Inc. HMT337 T/RH probe measures T/RH/VP/Dew Point at 2, 10, 20, and 40 meters, northeast side. (Prior to September 2008, Vaisala, Inc. HMP45D T/RH probes were used.)

Vaisala, Inc. PTB-220 Digital Barometer measures atmospheric pressure at 1.5 meters (Prior to September 2003, Vaisala, Inc. PTB-201A Digital Barometer was used.)

Scientific Technology, Inc. ORG-815-DR optical precipitation sensor attached to the southeast leg of the tower at 3 meters (removed from service in October 2003). 
Campbell Scientific, Inc. CR23X datalogger and Multiplexer in an enclosure at the base of the tower used to acquire the meteorological data.

\section{Present MET Instrumentation:}

Technical Services Laboratory, Inc. Model 1088 chilled mirror hygrometer at $3 \mathrm{~m}$, attached to the north leg of the tower. (previously, Meteolabor AG VTP6 Ventilated Thermohygrometer chilled mirror hygrometer at $3 \mathrm{~m}$, attached to the north leg of the tower, removed in October 2003).

Vaisala, Inc. PWD22 (with hood heaters) present weather sensor measures visibility, precipitation, and precipitation type at $2 \mathrm{~m}$, located south of the tower.

Vaisala, Inc. WS425 sonic anemometer at 2, 10, 20, and $40 \mathrm{~m}$, northeast side.

Vaisala, Inc. HMT337 T/RH probes measure T/RH/VP/Dew Point at 2, 10, 20, and $40 \mathrm{~m}$, northeast side.

Vaisala, Inc. PTB220 digital barometer measures station atmospheric pressure at $1.5 \mathrm{~m}$, located in an enclosure on the northwest side of tower.

Vaisala, Inc. WHP25 power supplies used at 2, 10, 20, $40 \mathrm{~m}$ to service the sensor collectors and instrumentation.

Campbell Scientific, Inc. CR3000 datalogger, multiplexer, and communication equipment, located in an enclosure on the northwest side of the tower.

\subsubsection{System Configuration and Measurement Methods}

Duplicate sets of instrumentation are used at heights of 25 meters and 60 meters on the SGP CF 60-meter tower. The probes and aspirated radiation shields are mounted on both the west and southeast elevator systems. A separate Campbell CR10X datalogger (previously, CR21X datalogger) is used for each level on the west elevator to measure sensor outputs, perform conversions to engineering units, and provide serial output for the remote collection of data from the datalogger memory. The same functions are accomplished for both levels on the southeast elevator with one CR10X. The meteorological measurements made with the system are as follows:

- Air temperature at two heights (25 meters and 60 meters)

- Relative humidity at two heights (25 meters and 60 meters)

- Aspiration status (west elevator only).

\subsubsection{Specifications}

The accuracies cited below for the meteorological sensors on the towers are generally those stated by the manufacturer. They are sensor-absolute accuracies and do not include the effects of system (i.e., datalogger) accuracies. Although it is not known how some of the manufacturers have determined sensor accuracy, it is properly the root square sum of any nonlinearity, hysteresis, and non-repeatability, usually referenced as percentage of full scale. 
The detection limit is normally restricted to the range (sometimes called Calibrated Operating Range) over which the accuracy applies. Some manufacturers also specify an Operating Temperature Range in which the sensor will function physically and electronically, even though the calibration may not be appropriate for use throughout that range. When no detection limits have been listed by the manufacturer, none is stated below.

\section{SGP 60-meter Tower:}

\section{West Elevator:}

Air temperature: Platinum Resistance Temperature Detector (PRTD), $100 \mathrm{ohm}$, Minco Products Inc., Model S853PD60X72; Detection Limits $-30^{\circ}$ to $40^{\circ} \mathrm{C}$; Operating Temperature Range $-40^{\circ}$ to $50^{\circ} \mathrm{C}$; Accuracy $+/-0.2^{\circ} \mathrm{C}$.

Relative Humidity: Before September 1996: Capacitive element, Vaisala Inc. Humicap; probe, Qualimetrics, Inc. Model 5120-E or 5134-E; Detection Limits 0\% to 100\% RH; Accuracy +/- 2\% $(0-80 \% \mathrm{RH})$ and $+/-3 \%(80-100 \%)$ over a temperature range of $-20^{\circ}$ to $50^{\circ} \mathrm{C}$; uncertainty of $\mathrm{RH}$ calibration $+/-1 \%$. After September 1996: Vaisala Inc. HMP35D or HMP45D; Humicap capacitive relative humidity element; Detection Limits $0 \%$ to $100 \% \mathrm{RH}$; Accuracy $+/-2 \%(0-90 \% \mathrm{RH})$ and $+/-3 \%$ (90-100\%) over a temperature range of $-20^{\circ}$ to $50^{\circ} \mathrm{C}$; uncertainty of $\mathrm{RH}$ calibration $+/-1 \%$.

Motor Aspirated Radiation Shield: Qualimetrics, Inc. Model 8151-B with flow sensor; nominal ventilation rate 1.83 meter per sec into inlet; radiation error $0.05^{\circ} \mathrm{C}$; operating temperature range -40 to $55^{\circ} \mathrm{C}$. Wind speeds over 10 meter per second, particularly from the south, can reduce the ventilation rate in the radiation shield; uncertainties are thought to be negligible due to this effect because radiation errors from heating of the radiation shield are reduced in high wind speeds.

Flow Sensor: Qualimetrics Model T450009; this sensor is a heated-element-type sensor that detects changes in air flow via a relay sensing a gap that depends on the maintenance of a particular temperature in a coil.

\section{Southeast Elevator:}

Temperature and Relative Humidity: Vaisala Inc. HMP35D or HMP45D.

Air Temperature: Platinum Resistance Temperature Detector (PRTD), $100 \mathrm{ohm}$; Detection Limits $-30^{\circ}$ to $40^{\circ} \mathrm{C}$; Operating Temperature Range $-40^{\circ}$ to $50^{\circ} \mathrm{C}$; Accuracy $+/-0.2^{\circ} \mathrm{C}$.

Relative Humidity: Humicap capacitive relative humidity element; Detection Limits $0 \%$ to $100 \%$ RH; Accuracy $+/-2 \%(0-90 \% \mathrm{RH})$ and $+/-3 \%(90-100 \%)$ over a temperature range of $-20^{\circ}$ to $50^{\circ} \mathrm{C}$; uncertainty of RH calibration $+/-1 \%$.

Motor Aspirated Radiation Shield: R.M. Young Model 43408/43482; nominal ventilation rate 3 meter per second into inlet; radiation error $0.05^{\circ} \mathrm{C}$; operating temperature range $-40^{\circ}$ to $55^{\circ} \mathrm{C}$. Uncertainties are thought to be negligible. 


\section{NSA 40-meter Tower:}

\section{Present MET Instrumentation:}

PWD22: Uncertainty: $+/-10 \%$ vis $10 \mathrm{~m}-10000 \mathrm{~m},+/-15 \%$ vis $10 \mathrm{~km}-20 \mathrm{~km}$; none for precip (detection $.05 \mathrm{~mm} / \mathrm{hr}$ or less within $10 \mathrm{~min}$ ) ; .operating conditions: -40 to $60 \mathrm{C}$, up to $100 \% \mathrm{RH}$, up to $60 \mathrm{~m} / \mathrm{s}$ winds.

CMH: Uncertainty: temp +/-0.5deg (-58 to $122 \mathrm{~F})$; $+/-1$ deg for remainder; dew point $+/-2 \mathrm{deg}$ RMS (30 to $86 \mathrm{~F}) ;+/-3 \mathrm{deg}$ RMS (-10 to $30 \mathrm{~F}) ;+/-4 \mathrm{deg}(-30$ to $-10 \mathrm{~F})$; . operating conditions: -80 to $130 \mathrm{~F}, 5-100 \% \mathrm{RH}$, winds up to $30 \mathrm{kts}$, up to 1 " ice loading.

WS425: measurement range of 1 to $65 \mathrm{~m} / \mathrm{s}$; speed accuracy of $+/-0.135$ or $3 \%$ of reading (whichever is greater); direction accuracy of $+/-2$ deg; operating temp of -55 to $55 \mathrm{C}$.

PTB220: uses Vaisala BAROCAP silicon capacitive absolute sensor; uncertainty $+/-0.15 \mathrm{hPa}$ (linearity $+/-0.1 \mathrm{hPa} / \mathrm{yr}$ ); range 50 to $1100 \mathrm{hPa}$; operating temp -40 to $60 \mathrm{C}$.

HMT337: uses Vaisala HUMICAP180 capacitive thin film polymer sensor for humidity and Pt100 resistive platinum sensor for temperature; . operating conditions are -70 to $180 \mathrm{C}, 0$ to $100 \% \mathrm{rh}$.

\section{Uncertainties:}

(temp)+/-0.2C@20C, gradually increasing to +/- 0.5C at -70C and +/- 0.6C at $180 \mathrm{C}$ (rh) -40 to $180 \mathrm{C}+/-(1.5+0.015 \mathrm{x}$ reading $) \%$;

additional calibration uncertainty is $+/-0.6 \%$ for $0-40 \%$ and $+/-1 \%$ for $40-97 \%$.

\subsection{Theory of Operation}

Temperature and relative humidity are measured at both 25 meters and 60 meters on both elevators (west and southeast sides) of the SGP CF tower. However, the aspirators used on the two sides are different: the west-side aspirators are made of metal and have a fairly low flow rate of $1.8 \mathrm{~L} / \mathrm{min}$, whereas the southeast-side aspirators are made of plastic and have a flow rate closer to $3 \mathrm{~L} / \mathrm{min}$. The temperature sensors on the two sides are also different: the southeast side uses the internal PRTD in the T/RH sensor, whereas the west side uses a PRTD that is separate from the T/RH sensor. Because of these differences, some difference in measurements from the two sides at the same height is expected. Ambient vapor pressure is calculated for both sides (west and southeast) and measurement heights (25 meters and 60 meters) from the measurements of temperature and relative humidity. This is accomplished using an instruction in the datalogger that calculates saturation vapor pressure from temperature. Vapor pressure (in $\mathrm{kPA}$ ) is then calculated from:

Vapor Pressure $=$ Relative Humidity/Saturation Vapor Pressure 


\subsection{Calibration}

\subsubsection{Theory}

Standard calibration procedures are followed for all temperature and relative humidity sensors used on the SGP CF 60-meter tower. See details below in Section 7.3.2.

\subsubsection{Procedures}

Vendor-recommended calibration procedures and calibration checks by the mentor are used to maintain the accuracy of the temperature and relative humidity sensors on the SGP CF tower.

Four-point relative humidity calibrations (at $0 \%, 12 \%, 75 \%$, and $97 \%$ ) above saturated salt solutions $(12 \%$ and $75 \%)$, zero air $(0 \%)$, and in almost-saturated air $(97 \%)$ are performed annually on the SGP CF tower HMP35D and HMP45D T/RH sensors by Vaisala, Inc. (after September 1996). The PRTD is also checked for accuracy by Vaisala, Inc. and the electronics adjusted to provide accurate temperature measurements. Previously, calibrations were performed by NovaLynx, Inc. (west elevator only) at 12\%, $40 \%$, and $75 \%$ above saturated salt solutions. This previous calibration technique often yielded incorrect calibration slopes, zero offsets, and a lack of sensitivity at relative humidity above $85 \%$.

The Minco Products, Inc. PRTDs on the west side are calibrated annually by the mentor with an ice bath check in the field (the elevator carriages are lowered to ground level for this procedure). The PRTD data are presently acquired with Campbell Scientific, Inc. CR10X dataloggers, using the built-in resistance-totemperature polynomial function. The inverse of a normalized resistance ratio at zero degrees Centigrade is entered into the datalogger system software as a multiplier.

The $\mathrm{T}$ and $\mathrm{RH}$ probes are also annually checked against each other and against ambient values using an aspirated psychrometer as the reference (both carriages from both sides are lowered to ground level for this procedure).

\subsubsection{History}

All calibration information is kept in the 60-Meter Tower Temperature - Relative Humidity Manual. Copies of the manual are maintained by site operations personnel at SGP CF and by the mentor. A large number of calibrations have been performed by the manufacturers and by the mentor and/or site operations personnel (in field). Calibration of west elevator relative humidity sensors was performed by NovaLynx before October 1996 and both east and west elevator sensors have been calibrated by Vaisala, Inc. since September 1996. The dates of calibration are listed below for each sensor serial number and/or location. W designates the west-facing elevator (side B); S designates the southeast-facing elevator (side A). The T/RH sensor serial number is the one that was left installed after calibration. MINCO PRTDs do not have serial numbers. Qualimetrics RH sensor numbers are three digits long. Vaisala T/RH sensor serial numbers are the long numbers. An asterisk indicates when a PRTD was replaced.

Temperature (PRTD):

Vendor calibrations: 
MINCO: MINCO PRTD: two sensors Mar 1993

MINCO PRTD: two sensors Mar 1996

Vaisala: HMP35D: S1720002 Jun 1997

HMP35D: S1720003 Jun 1997

HMP35D: unknown Oct 1997

HMP35D: S1720004 Jun 1997

HMP35D: S1720005 Jun 1997

HMP45D: S4520022 Jan 1998

HMP45D: S4520023 Jan 1998

HMP45D: S4930004 Jan 1998

HMP45D: S4930005 Jan 1998

Annual calibration performed on four Vaisala, Inc. T/RH sensors by Vaisala, Inc. since.

In-field calibrations (west elevator only):

W 25 meters 6 Feb 1996

23 May 1996

21 Oct 1996

5 Feb 1997

17 Jul 1998

19 May 1999

14 Aug 2000

8 Aug 2001

2 Aug 2002

15 Aug 2003

27 Sep 2004

5 Aug 2005

11 Oct 2006

26 Jul 2007

21 Sep 2009

annually in September or October thereafter (see in-field T/RH checks below)

W 60 meters 1 Mar 1993

6 Oct 1993

11 May 1994

15 Nov 1994

19 May 1995

19 Sep 1995

6 Feb 1996

23 May 1996 *

21 Oct 1996

5 Feb 1997

17 Jul 1998

19 May 1999

14 Aug 2000

8 Aug 2001

2 Aug 2002

15 Aug 2003

27 Sep 2004

5 Aug 2005 
11 Oct 2006

26 Jul 2007

21 Sep 2009

annually in September or October thereafter (see in-field T/RH checks below)

Temperature/Relative Humidity Probe:

Vendor calibrations:

$\begin{array}{lll}\text { Novalynx } & \text { S/N 109 } & \text { 29 Jul } 1992 \\ & \text { S/N 109 } & \text { 7 Jul 1993 } \\ & \text { S/N 231 } & \text { ? Nov 1995 } \\ & \text { S/N 226 } & \text { 5 Apr 1996 } \\ & \text { S/N 234 } & \text { 5 Apr 1996 } \\ & & \\ \text { Vaisala, Inc. } & \text { S/N 226 } & \text { 3 Dec 1996 } \\ & \text { S/N 234 } & \text { 3 Dec 1996 } \\ & \text { S/N 109 } & \text { 26 Feb 1997 } \\ & \text { S/N 231 } & \text { 26 Feb 1997 } \\ & \text { S/N 226 } & \text { 21 Aug 1997 } \\ & \text { S/N 234 } & \text { 21 Aug } 1997 \\ \text { HMP35D: } & \text { S1720002 } & \text { Mar 1997 } \\ \text { HMP35D: } & \text { S1720003 } & \text { Mar } 1997 \\ \text { HMP35D: } & \text { S1720004 } & \text { Mar } 1997 \\ \text { HMP35D: } & \text { S1720005 } & \text { Mar } 1997 \\ \text { HMP45D: } & \text { S4520022 } & \text { Jan } 1998 \\ \text { HMP45D: } & \text { S4520023 } & \text { Jan } 1998 \\ \text { HMP45D: } & \text { S4930004 } & \text { Jan } 1998 \\ \text { HMP45D: } & \text { S4930005 } & \text { Jan } 1998\end{array}$

Annual calibration performed on four Vaisala, Inc. T/RH sensors by Vaisala, Inc. since.

In-field checks of $\mathrm{T}$ and $\mathrm{RH}$ :

$\begin{array}{lll}\text { W } 25 \text { meters } & \text { S/N 234 } & \text { 6 Feb 1996 } \\ \text { S/N 226 } & \text { 19 Mar 1996 } \\ \text { S/N 231 } & \text { 25 Mar 1996 } \\ \text { S/N 231 } & \text { 22 May 1996 } \\ \text { S/N 231 } & \text { 21 Oct 1996 } \\ \text { S/N 231 } & \text { 4 Feb 1997 } \\ \text { S/N 234 } & \text { 5 Feb 1997 } \\ \text { S/N 109 } & \text { 13 Aug 1997 } \\ \text { S4930005 } & \text { 5 Nov 1997 } \\ \text { S4930004 } & \text { 17 Jul 1998 } \\ \text { S4930005 } & \text { 19 May 1999 } \\ \text { S4520022 } & \text { 14 Aug 2000 } \\ \text { S1720002 } & \text { 8 Aug 2001 }\end{array}$




\begin{tabular}{|c|c|c|}
\hline & S4520023 & 2 Aug 2002 \\
\hline & S1720004 & 15 Aug 2003 \\
\hline & S2920008 & 27 Sep 2004 \\
\hline & $\mathrm{S} 1720002$ & 5 Aug 2005 \\
\hline & S2920010 & 11 Oct 2006 \\
\hline & S1720002 & 26 Jul 2007 \\
\hline & S4930004 & 21 Sep 2009 \\
\hline & S2920011 & 18 Oct 2010 \\
\hline & S2920007 & 01 Nov 2011 \\
\hline & S2920008 & 09 Oct 2012 \\
\hline & S292007 & 28 Oct 2014 \\
\hline S 25 meters & $\mathrm{S} 1720003$ & 13 Aug 1997 \\
\hline & S1720005 & 26 Sep 1997 \\
\hline & S4520022 & 17 Jul 1998 \\
\hline & S1720004 & 19 May 1999 \\
\hline & $\mathrm{S} 1720002$ & 14 Aug 2000 \\
\hline & S1720004 & 8 Aug 2001 \\
\hline & S4520022 & 2 Aug 2002 \\
\hline & S4520015 & 15 Aug 2003 (replaced 10 Feb 2004, S2920011, no cal.) \\
\hline & S4930004 & 27 Sep 2004 \\
\hline & S2920009 & 4 Aug 2005 \\
\hline & S4930004 & 11 Oct 2006 \\
\hline & S2920009 & 26 Jul 2007 \\
\hline & S2920008 & 21 Sep 2009 \\
\hline & S4520023 & 18 Oct 2010 \\
\hline & S4520015 & 01 Nov 2011 \\
\hline & S2920011 & 09 Oct 2012 \\
\hline & S2920010 & 28 Oct 2014 \\
\hline W 60 meters & $\mathrm{S} / \mathrm{N} 109$ & 11 Mar 1993 \\
\hline & $\mathrm{S} / \mathrm{N} 231$ & 6 Oct 1993 \\
\hline & $\mathrm{S} / \mathrm{N} 231$ & 7 Oct 1993 \\
\hline & $\mathrm{S} / \mathrm{N} 231$ & 11 May 1994 \\
\hline & $\mathrm{S} / \mathrm{N} 231$ & 15 Nov 1994 \\
\hline & $\mathrm{S} / \mathrm{N} 109$ & 19 May 1995 \\
\hline & $\mathrm{S} / \mathrm{N} 109$ & 19 Sep 1995 \\
\hline & $\mathrm{S} / \mathrm{N} 109$ & 6 Feb 1996 \\
\hline & S/N 234 & 22 May 1996 \\
\hline & $\mathrm{S} / \mathrm{N} 226$ & 21 Oct 1996 \\
\hline & $\mathrm{S} / \mathrm{N} 109$ & 4 Feb 1997 \\
\hline & $\mathrm{S} / \mathrm{N} 226$ & 5 Feb 1997 \\
\hline & S/N 231 & 13 Aug 1997 \\
\hline & S1720004 & 5 Nov 1997 \\
\hline & S4520023 & 17 Jul 1998 \\
\hline
\end{tabular}




\begin{tabular}{|c|c|c|}
\hline & S1720003 & 19 May 1999 \\
\hline & S4930004 & 14 Aug 2000 \\
\hline & S4930005 & 8 Aug 2001 \\
\hline & SW012001 & 12 Aug 2002 \\
\hline & S4930005 & 21 Feb 2003 \\
\hline & S1720002 & 15 Aug 2003 \\
\hline & S2920010 & 27 Sep 2004 \\
\hline & S1720004 & 5 Aug 2005 \\
\hline & S2920008 & 11 Oct 2006 \\
\hline & S1720004 & 26 Jul 2007 \\
\hline & S4520015 & 21 Sep 2009 \\
\hline & S2920009 & 18 Oct 2010 \\
\hline & S2920010 & 01 Nov 2011 \\
\hline & S2920009 & 09 Oct 2012 \\
\hline & S4520015 & 28 Oct 2014 \\
\hline S 60 meters & S1720002 & 13 Aug 1997 \\
\hline & S1720002 & 17 Jul 1998 \\
\hline & S1720005 & 19 May 1999 \\
\hline & S4520023 & 14 Aug 2000 \\
\hline & S1720003 & 8 Aug 2001 \\
\hline & S4930004 & 2 Aug 2002 \\
\hline & $\mathrm{S} 1720003$ & 25 Oct 2002 \\
\hline & S4930004 & 15 Aug 2003 (replaced 10 Feb 2004, S2920009, no cal.) \\
\hline & S4520015 & 27 Sep 2004 \\
\hline & S2920011 & 4 Aug 2005 \\
\hline & S4520015 & 11 Oct 2006 \\
\hline & S2920011 & 26 Jul 2007 \\
\hline & S2920010 & 21 Sep 2009 \\
\hline & S4520022 & 18 Oct 2010 \\
\hline & S4520023 & 01 Nov 2011 \\
\hline & S4930004 & 09 Oct 2012 \\
\hline & S4520023 & 28 Oct 2014 \\
\hline
\end{tabular}

\subsection{Operation and Maintenance}

\subsubsection{User Manual}

Copies of the SGP CF tower and elevator user manuals are kept at SGP CF and at the mentor's office. A copy of the SGP Okmulgee tower user manual is kept at SGP CF and at the mentor's office. Copies of the NSA tower and elevator user manuals are kept at NSA Barrow and at the mentor's office.

SGP CF and Okmulgee maintenance and system checks are performed in accordance with procedures developed by SGP Site Operations and the mentor. These procedures are maintained in print form at SGP $\mathrm{CF}$ and in digital form on Site Operations laptops taken into the field; these proceduresinvolve 
maintenance and checks on the various sensors on these towers. A NSA tower maintenance procedures document is maintained at NSA Barrow and includes maintenance and checks on the various sensors on the tower.

\section{Software Documentation:}

The SGP CF tower tower25, tower60, and twr2560 programs are maintained on SGP Site Operations computers at the SGP CF, on laptops used by Site Operations, in print form by SGP Site Operations, and by the mentor (print and digital copies).

\subsubsection{Routine and Corrective Maintenance Documentation}

Print copies of the annual SGP CF tower in-field calibration reports are maintained at SGP CF and by the mentor.

\subsubsection{Software Documentation}

This section is not applicable to this instrument.

\subsubsection{Additional Documentation}

This section is not applicable to this instrument.

\subsection{Glossary}

See the ARM Glossary.

\subsection{Acronyms}

$\begin{array}{ll}\text { ARM } & \text { Atmospheric Radiation Measurement Climate Research Facility } \\ \text { CF } & \text { Central Facility } \\ \mathrm{CO}_{2} \text { FLX } & \text { Carbon Dioxide Flux Measurement System } \\ \text { DQ } & \text { Data Quality } \\ \text { DQ Explorer } & \text { Data Quality Explorer } \\ \text { ECOR } & \text { Eddy Correlation System } \\ \text { GPS } & \text { global positioning system } \\ \text { MFR } & \text { Multi-Filter Radiometer } \\ \text { NSA } & \text { North Slope of Alaska } \\ \text { PGS } & \text { precision gas system } \\ \text { PRTD } & \text { Platinum Resistance Temperature Detector } \\ \text { RMS } & \text { root mean square } \\ \text { SGP } & \text { Southern Great Plains } \\ \text { SIRS } & \text { Solar and Infrared Station } \\ \text { MET } & \text { Surface Meteorological Instrumentation } \\ \text { VAP } & \text { Value Added Product }\end{array}$

Also, see the ARM Acronyms and Abbreviations. 


\subsection{Citable References}

Revercomb, HE, DD Turner, DC Tobin, RO Knuteson, WF Feltz, J Barnard, J Bosenberg, S Clough, D Cook, R Ferrare, J Goldsmith, S Gutman, R Halthore, B Lesht, J Liljegren, H Linne, J Michalsky, V Morris, W Porch, S Richardson, B Schmid, M Splitt, T Van Hove, E Westwater, and D Whiteman. 2003. "The ARM Program's water vapor intensive observation periods - overview, initial accomplishments, and future challenges." Bulletin of the American Meteorological Society 84: 217-236, doi:10.1175/BAMS-84-2-217. 


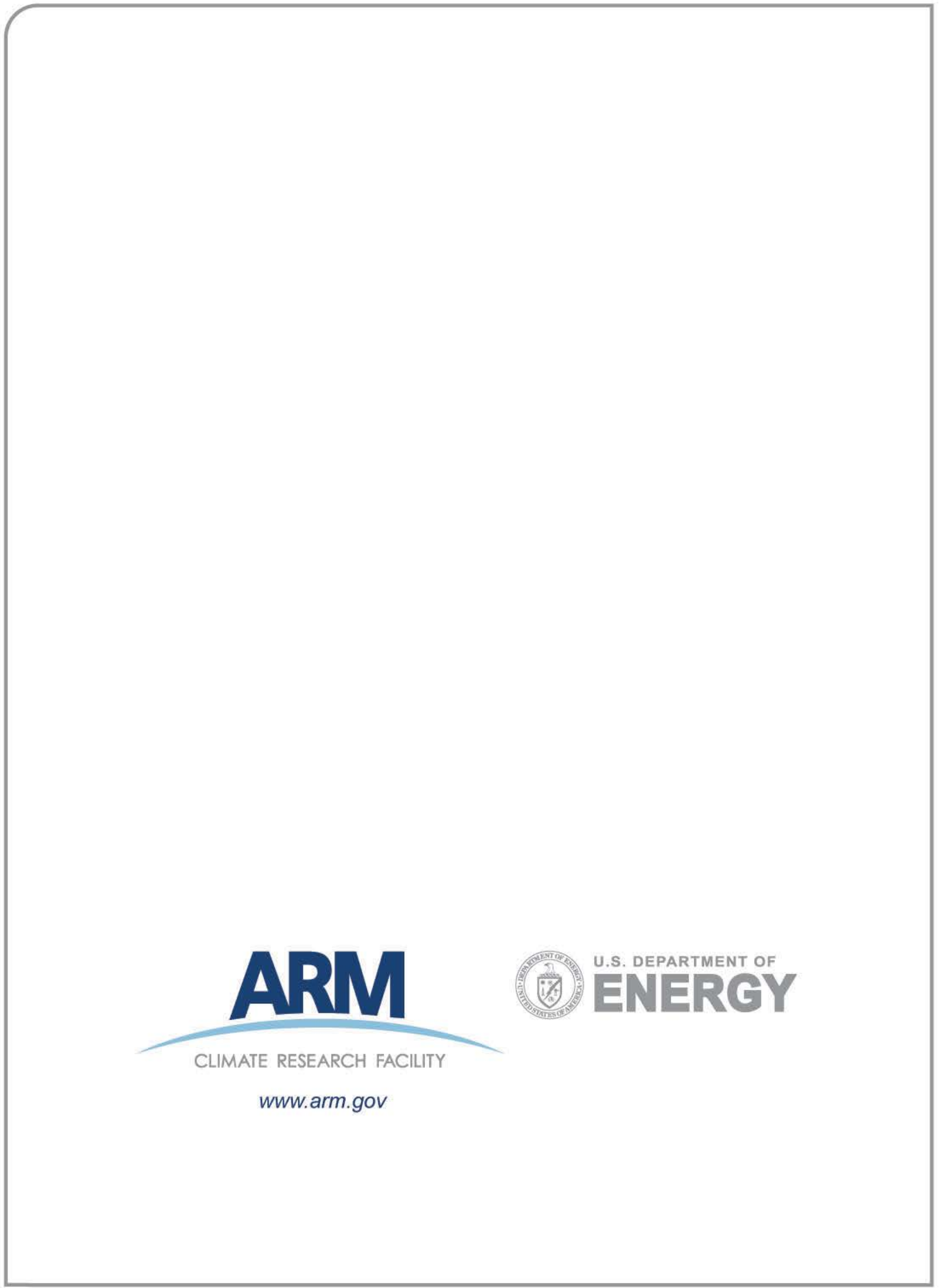

